Bryan C. Taylor*

\title{
Yours, Mine and Ours: Theorizing the Global Articulation of Qualitative Research Methods and Academic Disciplines
}

\begin{abstract}
Two current forms of globalization are inherently interesting to academic qualitative researchers. The first is the globalization of qualitative research methods themselves. The second is the globalization of academic disciplines in which those methods are institutionalized as a valuable resource for professional practices of teaching and scholarly research. This essay argues that patterns in existing discussion of these two trends create an opportunity for innovative scholarship. That opportunity involves reflexively leveraging qualitative research methods to study the simultaneous negotiation by academic communities of both qualitative methods and their professional discipline. Five theories that serve to develop this opportunity are reviewed, focusing on their related benefits and limitations, and the specific research questions they yield. The essay concludes by synthesizing distinctive commitments of this proposed research program.
\end{abstract}

Keywords: globalization, academic disciplines, qualitative methods

\section{Introduction: The Globalization of Qualitative Research Methods}

Within the past two decades, a growing number of scholarly voices have testified to the global circulation of qualitative research methods among social science disciplines (see Taylor and Lindlof, 2013). Consistently, those voices address how this circulation creates new challenges and opportunities which affect disciplinary practices of teaching and research, and stimulate a search by disciplinary members for new forms of community which may support their response.

In this process, commentators navigate an overlapping series of discourses through which social scientists have conceptualized the relationship between qualitative methods and contemporary globalization. In the first discourse, qualitative researchers have engaged globalization as an urgent confluence of changing conditions - principally, destabilizing flows of material and symbolic phenomena across traditional geopolitical boundaries - which has affected their chosen objects of study, and provoked revision of their existing theory and methodology. In a second discourse, critical researchers have sought to de-colonize historical traditions of qualitative research which have contributed to the hegemony of modern Western culture, and inhibited the development of authentic knowledge and voice among indigenous peoples. Currently, these researchers also defend the integrity of qualitative methods against a powerful backlash by neo-liberal institutions seeking to reestablish positivist protocols for the production of knowledge claims.

* University of Colorado-Boulder (USA); bryan.taylor@colorado.edu. 
In this essay, I am concerned with a third - and growing - discourse in this series. Here, social scientists conceptualize qualitative research methods as commodities circulating in global economies of academic knowledge and practice. Here, we are concerned with the provenance of qualitative methods as artifacts developed among American, British, and European scholarly communities during the nineteenth and twentieth centuries. We seek to understand the various forms of "supply and demand" which have structured the global flows of qualitative research, and which have produced marked inequity between higher educational institutions located in North America and Europe, and those located in the global East and South.

We pursue this inquiry for at least two reasons. The first is that it may encourage the development of more equitable structures of global knowledge production, and more flexible and innovative methodologies capable of engaging the complex manifestations of global flows (e.g., migration and pandemic; Flick \& Rohnsch, 2015). Beyond these purposes, however, this inquiry arises because the global institution of qualitative research has sufficiently matured so that it is now willing and able to investigate its increasingly diverse components. Moved by curiosity to explore their international community, qualitative researchers are developing enhanced understanding of themselves as professional actors engaged in local situations, negotiating the opportunities and constraints afforded by available resources for addressing their unique needs - activities which, in turn, shape the evolving conditions of their work. In this sense, qualitative researchers are reflexively mobilizing the spirit of qualitative inquiry to better understand the global cultures of qualitative research.

\section{The Globalization of Higher-Educational Institutions and Academic Disciplines}

Within the sphere of post-industrial higher-education, of course, this curiosity is not limited to methodological communities. It is also an urgent matter for colleges and universities, as they assess the threats and opportunities generated by contemporary globalization for their traditional revenue streams and operations (Becher \& Trowler, 2001). Within this increasingly "borderless" environment created by the end of the Cold War and the ongoing modernization of economies and societies in regions such as South Asia and Eastern Europe, higher-educational institutions are increasingly undertaking massive, strategic -and oftentraumatic - change programs. These programs are stimulated by interrelated trends, such as defunding by state governments, the growing centrality of techno-science and intellectual property for international markets, and the emergence of various economies of 'knowledge,' 'affect,' 'experience,' and 'risk' which have revised (i.e., instrumentalized and commodified) the value conventionally attributed to higher-educational learning. Related campaigns range from defending against competition by both local, for-profit operators and global mega-universities, to more opportunistic ventures (particularly among U.S. institutions; see Kleypas $\&$ McDougall, 2012), such as selective development of courses and programs for online delivery (Umpleby, et al., 2009); opening of new campuses to deliver programs in foreign markets; partnering with industry in research ventures; organizational restructuring; intensifying managerial oversight and budgetary efficiency, and recruiting growing numbers of foreign students created by the regional emergence of aspirational, middle-class cultures.

This evolution in the relationship between higher educational institutions and their central authorities creates a volatile mix of constraints and opportunities for their disciplinary units. 
My focus here is on the process (parallel to that occurring among qualitative researchers) in which maturing academic disciplines seek to understand the diverse limbs and organs of their increasingly-international bodies. Here, related projects seek to inventory and map the total manifestations of a discipline's professional knowledge and practice. They consider how these manifestations alternately sustain and vary the ideal attributes of a discipline's "tribal" identity (i.e., as unique and cohesive), manifest as distinctive qualities of its official structure and culture (Becher \& Parry, 2005). These elements include: external boundaries with other disciplines (e.g., loose and cosmopolitan vs. rigid and provincial); relations with prominent stakeholders such as industries, professions, publics, funding agencies, and policy-makers; epistemological orientations; theoretical traditions; prioritized research programs; methodological practices; pedagogy, curriculum, and degree offerings; forms of self-governance and development (e.g., professional associations); and internal structuring of sub-fields (e.g., hierarchical vs. egalitarian). Frequently, these investigations are conducted within the context of particular nation-states and global regions, and focus on the correspondence between disciplinary trajectories and the historical development of associated social, economic, and political institutions. Ultimately, such projects cultivate a narrative sufficient to represent the integrity of "the global discipline." Ideally, such accounts serve strategic narratives of disciplinary identity and interest - for example, as a legitimate, effective, growing enterprise entitled to increased investment of scarce resources.

\section{Statement of Purpose}

Although I have so far depicted the globalization of qualitative research methods and academic disciplines as-if parallel trends, they in fact overlap. This is because the social science disciplines form a principal, durable medium for the globalization of qualitative research methods. In turn, the "migration" (Flick, 2014) of qualitative research methods creates a prominent "boundary object" or "contact zone" through which the dispersed members of global disciplines may approach or avoid idealized states of mutual understanding and increased coordination (Lamont \& Molnar, 2002). This overlap yields at least four (admittedly fine-grained) distinctions among related research narratives. First, those narratives may depict the general history and character of qualitative research, as it is practiced within a broad interdisciplinary enterprise, located in a specific state/region (e.g., Adam \& Podmenik, 2005; Weil, 2005; Torrance, 2014). A second genre depicts interdisciplinary qualitative research following a specific topic or program, as conducted either globally (e.g., Charmaz, 2014), or within a specific state/region (Knoblauch, et al., 2005). Third, researchers may portray the qualitative research traditions of a specific discipline, as it is located in a specific state/region (e.g., Konecki, et al., 2005). Finally, they may study of the role played by globalizing qualitative methods in the development of a specific discipline, emerging in a specific state/region.

Review of related literatures indicates a predominance of studies in the first, second, and third categories. This output has been influenced by various scholarly calls: by individual figures such as Alasutaari (2004), who has advocated for the development of a "spatial" narrative to offset the homogenizing logic encoded in "temporal" narratives of qualitative methods evolution; by international conferences such as the International Congress of Qualitative Inquiry, held at the University of Illinois, Urbana-Champaign (http://icqi.org/); and by academ- 
ic journals such as Qualitative Inquiry and Forum: Qualitative Social Research (http://www.qualitative-research.net/index.php/fqs), which regularly publish related studies and special issues. In response, qualitative researchers from global "peripheries" such as Ibero-America (Puebla, et al., 2006) and Asia (Hsiung, 2012) have documented how "their" methods have historically developed through interactions occurring within and between specific networks of actors, knowledges, texts, and practices - which have, in turn, been influenced by overarching conditions such as enduring religious-ethnic conflict (Schubotz, 2005). These accounts typically depict "glocalized" encounters between a hegemonic, Anglo-American core tradition, and localized articulations of national / regional culture, (inter-) disciplinarity, and higher-educational institutionalization. These encounters produce distinctively "hybrid," "creolized" - and sometimes idiosyncratic - configurations of qualitative research methodology (Angermuller,2005).

The vast majority of these accounts involve case studies which review related archives and contemporary literatures, employing relatively informal (and even impressionistic) methodologies such as portraiture and "cartography" (Valles \& Baer, 2005; Eberle \& Elliker, 2005). A second, much rarer, genre involves empirical study of qualitative research communities. These studies report on recent strategic initiatives by (inter-)national bodies seeking to inventory geographically-specific, (inter-)disciplinary networks of qualitative researchers, and to consolidate the resources supporting their productivity (e.g., Eberle \& Elliker, 2005; Henwood \& Laing, 2005). These studies largely use survey and data-base methods to establish similarities, differences, and trends in the methodological practices of these groups, and to assess their implications for stakeholder relationships.

Collectively, these projects provide valuable insight into the global dynamics of increasingly mobile qualitative methodology. Nonetheless, we may discern two gaps in this literature, which create opportunities for extending and innovating current discussion. The first gap involves the relative lack of narratives studying the role of methodological globalization in the development of disciplinary globalization. Here, we may investigate precisely how the global diffusion of research methods influences the local development of academic disciplines. A second - and somewhat ironic - gap involves a lack of studies utilizing the resources of qualitative methods themselves to investigate these dynamics. Here, empirical researchers can leverage means such as participant-observation and interviewing to more richly depict the evolving communal meanings and practices associated with glocalized articulations of methodology and disciplinarity. In this process, they may continue to improve the historically "pitiful and poverty-stricken" body of qualitative research on "actual everyday life in academic institutions" (P. Treichler, in Fiske, 1992, p. 167).

\section{Theoretical Overview}

We are now able to specify our proposed object of study. It is the 'glocalization' of qualitative research methodology, as that phenomenon manifests within specific intersections of three historical and cultural contexts: those of national/regional identity, academic-disciplinary identity, and higher-educational institutionalization. This proposal assumes that the ongoing globalization of both academic disciplines and qualitative research methods are articulated in these manifestations. More innovatively, it assumes that qualitative methods may themselves be utilized to investigate these articulations as significant matters of disci- 
plinary culture and professional development. This proposal finds support in Goodall's (1999, p. 487) account of academic communities as organic phenomena, animated by a pervasive, sensitive relationality:

[They] exist within a complex web of families, friendships, departments, academic institutions, cities and states, educational hierarchies, professional organizations, and world histories, all of which can and do influence ... our identities, our understandings, our professional and personal goals, what and how we write, how we live... A change in any one strand of this intricate web necessarily means changes in some, if not all, of the rest. Everything is connected.

What phenomena might such a study consider? Existing discussions suggest potential units of analysis. Foremost are the meanings and practices by which the members of a local academic community negotiate the simultaneous globalization of both their discipline and qualitative research methods. Here, we are drawn to the collective enactment of change, as potential innovations of local-disciplinary tradition are identified, promoted, voluntarily incorporated, and/or externally imposed (Becher \& Trowler, 2001, pp. 95-102). We consider how various characterizations of qualitative methods - as 'fashionable fad,' 'legitimate option,' 'valuable asset,' or 'inevitable requirement' - are constructed and circulated among community members. We ask what pragmatic, moral, and political work such attributions $d o$ in reproducing and transforming disciplinary cultures. We investigate how academic communities orient to the globalization of qualitative research in managing their local disciplinary orthodoxy - including "methodological fortresses ... which ... provide defensive bulwarks against external criticism" (Somekh, et al., 2005, p. 2). We may consider how these changes manifest for disciplinary members at the level of their lived experience, as they engage in ongoing sensemaking and narration of their own and others' evolving identities. Such narratives may depict forms of membership characterized by qualities such as desire, ambition, commitment, vulnerability, competency, wisdom, and resistance. As a result, finally, we may better understand how different social science disciplines uniquely appropriate the affordances of methodological traditions (Somekh, et al., 2005).

Beyond this framing, the use of qualitative methods for such a project presupposes a theoretical agenda that can adequately guide the collection and analysis of related data, and ensure the production of relevant, credible findings. To that end, I review below five theoretical traditions which serve this purpose. In sequence, they include: the diffusion of innovation; the sociology of generations; speech, discourse, and interpretive community; community of practice; and finally, Bourdieu's theory of academic habitus. I focus here on elaborating their distinctive premises and claims, their benefits and limitations for this project, and the research questions they yield.

\subsection{The Diffusion of Innovation}

As famously developed by communication scholar Everett Rogers (2003), our first theory focuses on the mediated relationship between producers and consumers of innovative knowledge, practice, and technology. Drawing on historical case-studies of Western-provided aid and development, this theory emphasizes how the decisions of societal members to adopt novel belief-systems and commodities, made in response to their producers' persuasive campaigns, hinge on several factors. These include relevant cultural norms and psychological predispositions (e.g., tolerance of uncertainty and risk); demonstrable affordances of the innovation (e.g., cost, simplicity, and effectiveness); exposure to informative and influential communication by 
friends, family, and community members (e.g., serving as 'opinion leaders'); and subsequent attribution of the relative benefits and liabilities of adoption (e.g., opportunity cost). The theory typifies adopters and the phases of their decision processes, corresponding to a rising, Sshaped curve. It depicts growing stages of learning and participation, leading from awareness, interest, and evaluation, to trial and adoption. Its spectrum of adopter profiles ranges from adventuresome and highly-educated 'Innovators' to isolated, orthodox, and fearful 'Laggards.' The theory foregrounds the interdependence of mass media campaigns and interpersonal networks (e.g., in producing peer pressure), as well as the degree of similarity displayed between communicators, as factors influencing the rate and extent of ultimate adoption. The theory's enduring contribution has been to elaborate the contingency of communal learning, and the consequentiality of imitative behavior (Dearing, 2006).

For our purposes, the benefits of this theory include its depiction of community members confronting change, and collaboratively negotiating their responses. It emphasizes the communication networks through which they are informed and influenced in forming these responses. It indicates the role of communal norms, values, and beliefs in shaping members' perceptions of apparent risks and opportunities surrounding adoption. It emphasizes the role of key individuals and groups in alternately facilitating and impeding adoption, and proposes a threshold of adoption (i.e., critical mass) at which point the innovation may be deemed normalized.

Relevant limitations, however, include the theory's provenance in aid, development, and marketing contexts, which may limit its effectiveness for studying relatively-autonomous and highly-educated professionals deliberating potentially-optional and incremental change in their intellectual traditions. Its relatively objectivist ontology, further, may not support interpretivist analysis of the process by which academic communities selectively construct multiple, competing, and contested artifacts. Similarly, its modeling of adoption phases may prematurely promote a logic of necessity and inevitability, obscuring the complexity of partial and ambivalent accommodations. As well, the theory does not primarily model adoption conducted amid the simultaneity of changing contexts. Finally, its etic invocation of influential factors and decision-making types potentially conflicts with the emic commitment in qualitative research to empathic understanding and inductive explanation of participant experience.

Considering these benefits and limitations, research questions derived from this theory would include:

- What are the communication networks through which the members of a local academic community are informed and influenced concerning the potential adoption of qualitative research methods? What are the characteristic patterns of communication in those networks?

- How do the existing norms, values and beliefs of a local academic community shape its members' perceptions of qualitative methods as potential disciplinary innovation, and influence their construction of related artifacts?

- How is the adoption of qualitative research methods in an academic community related to its simultaneous adoption of other disciplinary innovations?

\subsection{The Sociology of Generations}

In his essay entitled "The Sociological Problem of Generations," Karl Mannheim (1952/2009) identified that eponymous gap in existing social theory, raising the issue of how the temporal situation of social groups may distinguish their contributions to societal development. Immediately, Mannheim noted that the coincidence of individuals' biographies with- 
in a historical cohort does not necessitate their shared membership in a community. Alternately, generational members approach that status as they are organized by their shared location in social structure, which "limit[s] them to a specific range of potential experience ... [and] self-expression" (pp. 168-169). Subsequently, while living actors at any given moment all share access to a basic fund of social experience, they are distinguished by their generational "approach" to selecting and utilizing "the accumulated cultural heritage" (p. 170). This archive is institutionalized anew by each generation, as its members' life course yields experiences which first require - and then confirm - their prioritization of available knowledge as tools for successful living.

This condition influences the processes of social change in that mortal humans are continuously entering and disappearing from communities, requiring their "stratified" generations to collaborate in reproducing cultural heritage. The stability of this transition is complicated by the "fresh contact" of new generations with inherited knowledge as a mediated abstraction. This condition encourages - but does not determine - these groups' development of "novel approaches" to engaging cultural tradition, arising from their immediate experience of evolving priorities, and from their actualization of potential group identities and interests. This ongoing emergence of "fresh selection," notes Mannheim, "facilitates reevaluation of our inventory and teaches us both to forget that which is no longer useful and to covet that which has yet to be won" (p. 173). The young, in other words, are not bound to conceptualize or utilize cultural knowledge according to the priorities arbitrarily developed by preceding generations. The potential for inter-generational conflict here is buffered as "intermediary" generations oriented to both tradition and innovation regulate the tempo of change.

This conceptualization, of course, does not presume intra-generational uniformity or consensus. As Pilcher (1994, p. 483) notes in her assessment of Mannheim's theory, "contemporaneous individuals are ... internally stratified ... by their geographical and cultural location; by their actual as opposed to potential participation in the social and intellectual currents of their time and place; and by their differing responses to a particular situation so that there may develop opposing generational 'units'." Nonetheless, for Mannheim, social actors may be considered generational members to the extent they share a unique, temporal experience of concrete historical problems, an agenda for responding to those problems based on their modification of inherited tradition, and a repertoire of practices for accomplishing that modification.

For our purposes, this theory beneficially clarifies how evolving response by academic communities to the globalization of qualitative research and their disciplines is not necessarily uniform or consistent. Instead, that response may be conceptualized and enacted differently both at any given moment, and over time - by generational groups guided by distinctive premises and agendas. The theory also establishes how change is temporally configured in the forms of collaboration and competition conducted within and between generations, as their members alternately produce, inherit, and modify cultural tradition. Fortuitously, Mannheim's theory has been tentatively applied in at least one study of academic community, focused on stratified conceptions of professional identity and career opportunity among contemporary Australian sociologists (Marshall \& Robinson, 2014).

As Pilcher (1994) notes, however, Mannheim's argument is largely theoretical, and does not provide empirical researchers with guidelines for actually studying this process. Appropriately for our proposed project, one solution involves examining the discourse of generational members as "the empirical location of knowledge" (p. 493). Additionally, Mannheim is vague concerning protocols for validating related research findings. He implies that re- 
searchers must first, characterize a primary generational sensibility serving as a ground for subcultural variation, and second, reconcile that account with known features of that generation's social, political, and economic contexts.

Bearing these factors in mind, this theory yields the following research questions:

- How does the collective response of an academic community to the globalization of qualitative methods and its discipline configure the unique experiences and agendas of its overlapping generations?

- How do those generations interact, both synchronically and diachronically, to construct that response?

\subsection{Speech/Discourse/Interpretive Community}

Here, we are concerned with a group of related theories addressing the importance of symbolic expression and interpretation for maintaining a community's distinctive norms, values and beliefs, and for constituting the practices which certify communal standards for legitimate membership. We build here from Hymes' (1972) conception of "speech community" as a social group defined by distinctive practices of communication - including the use of rules guiding who may speak on a particular topic, when, where, with whom, and how. In this perspective, communal membership is demonstrated in members' shared knowledge and coordinated practice, as these are oriented to cultural categories for relevant speech situations, their component events and acts, and their accompanying styles of speaking.

Our second concept of "discourse community," subsequently, directs attention to the ways that shared norms, values, and beliefs structure the form and content of spoken and written communication, exchanged between the members of voluntary, goal-oriented social groups (Borg, 2003; Olsen, 1993). It focuses on the quality of communicative performances which lead audiences to deem them both appropriate and effective. It depicts community members as engaged in ongoing processes of expression, impression formation, and evaluation, which serve to maintain, negotiate, and transform related standards of communication competence.

"Interpretive community," finally, signals the role of textual interpretation in shaping communal identity (Fish, 1980; Lindlof, forthcoming). Here, readers and other kinds of audiences are networked through their shared modes of active sensemaking of media artifacts, and their preferences of for performing that sensemaking in their ongoing conduct of everyday life. In this perspective, texts do not possess innate authority; instead, they serve as raw, indeterminate, semiotic resources which may be creatively appropriated by social groups to serve their unique projects. Interpretive communities are sustained not only in their members' consistent performance of these strategies, but also through their response to divergent and deviant performances, and their ongoing debate over whether and how to change those strategies to accommodate evolving situations.

For our purposes, this collection of perspectives usefully focuses on academic-disciplines as communities that are centrally - perhaps even obsessively - organized around the phenomena of discursive / textual production and interpretation (Duff, 2010). It depicts ongoing opportunities and dilemmas created for professional socialization by members' learning about preferred strategies for interpreting canonical texts, and their assimilation of complex rules for designing and performing associated communication (e.g., stance-taking in relation to intellectual controversy). While related studies often focus on the trials of novice members (i.e., students), the perspective may also be cultivated to engage the ongoing socialization of $\mathrm{ma}$ - 
ture professionals responding to textual waves of disciplinary and methodological globalization. It may also depict the dialogic, mutual influence exchanged between novices, veterans, and their intermediaries in academic communities, as those members orient to change, and potentially produce new forms of literacy and performance.

Research questions derived from this collection of theories thus include the following:

- What are the textual economies (e.g., works and networks) through which an academic-disciplinary community engages the globalization of qualitative research methods?

- How do traditional discursive and interpretive practices in an academic-disciplinary community (e.g., citation protocols and classroom pedagogy) change to accommodate the globalization of qualitative research methods?

\subsection{Community of Practice}

Eschewing the arid structuralism of network studies and the geographical determinism of the speech community concept, this theoretical tradition conceptualizes its eponymous groups as "people who engage in a process of collective learning in a shared domain of human endeavor" (Wenger, n.p.). It emphasizes the passionate, unifying commitment displayed among related group members to a distinctive interest or purpose (e.g., achieving aesthetic excellence and commercial success in fiction-writing); the contexts in which they regularly meet to cultivate affiliative and collaborative relationships (e.g., writing workshops); and finally, their ritualized performance of activities (e.g., reading and discussing each other's' work-inprogress) which enact these contexts.

Innovatively, the theory identifies how such communities self-organize - arising spontaneously in response to the recognition of unmet needs among individuals and groups with common interests, and who subsequently maintain their enterprise informally, independent of conventional organizational structures. It thus celebrates the unruly potential for group learning to exceed officially-designated moments and spaces, and enroll a growing range of actors and events. The theory is also concerned with how such groups move through stages of development characterized by distinctive forms of interaction (e.g., coalescing, dispersing, and commemorating), and also with the consequences of those activities for related institutions (e.g., stewardship of valuable competencies, cultivation of alternate identities, etc.). The potential for beneficial outcomes here inspires the theory's normative concern with how members and their sponsoring organizations may successfully nurture these kinds of groups (e.g., through internal leadership and official legitimation).

For our purposes, this tradition usefully theorizes the process through which academic professionals sharing an interest in methodological innovation may form a community, both within and outside traditional disciplinary structures, to cultivate understanding and mastery of related knowledge and practice (Becher \& Parry, 2005). It suggests how such communities may serve as testing grounds for disciplinary adoption of 'new' research methods. It emphasizes the contingency of official sanction by larger institutions which is required for their widespread adoption. It thus implicates two scenes of interaction: that occurring internally among the members of academic communities of practice, as they develop their standards of membership, and also externally, as they represent the outcomes of their learning to disciplinary gatekeepers.

Nonetheless, by emphasizing the potential for diverse manifestations of academic communities of practice, this tradition alternately affirms and subverts the presumed stability and 
influence of disciplines as learning contexts. Klein and Hirschhiem (2008), for example, argue that correspondence with academic community of practice is most likely to occur among developing disciplines. Additionally, our proposed use of this theory diverges from its traditional focus on student, professional staff, and novice-faculty learner groups (e.g., Jawitz, 2007; McDonald \& Star, 2008; Otten, 2009). This is necessary to emphasize the full range of inter-generational configurations that may emerge to negotiate specific disciplinary transitions (Andrew, et al., 2009). Here, we draw support from the argument that professional disciplines endure as an overarching source of fundamental ideas which contextualize the situated development by academic communities of practical knowledge as a relevant, legitimate, and fruitful enterprise (Becher \& Parry, 2005).

Finally, researchers have already used the theory to partly address the features of our chosen object. Churchman and Stehlik (2007), for example, have conceptualized alternative structures enabling the members of higher-educational institutions to mitigate the disruption of their traditional academic community by neo-liberal reforms. Additionally, in their attempt to map the communities constituting a "pedagogical culture" surrounding social science research methods, Wagner, et al. (2011) identify a genre of journal-based discussion devoted to "the way in which specific disciplines use an approach to teach research methods" (p. 78) - with many of these specifically debating the merits of qualitative methods.

Based on this discussion, related research questions include:

- How do local academic communities of practice form to engage with the globalization of qualitative research methods?

- How do their operations influence disciplinary development within local and regional institutions of higher-education?

\subsection{Bourdieu's Theory of Academic Fields and Habitus}

Pierre Bourdieu's oeuvre of theory and research is large and exceedingly complex, and his ideas evolved significantly over the course of his career. This is not the occasion for a detailed, comprehensive review. Generally, Bourdieu (1977) was concerned with the dynamics of power in society, and the subtle ways it is exchanged within and across contexts. Bourdieu argued that individuals simultaneously occupy multiple positions in social space - most significantly, in fields which configure institutional forces to produce distinctive, relatively autonomous forms of play, competition, and conflict. We are subsequently defined not only by our memberships in objective structures (e.g., of class), but by the distinctive forms of capital (e.g., valuable forms of property, membership, status, qualification, knowledge, and skill) we are able to develop and use in our conduct of relationships within fields.

Specifically, Bourdieu (1979/1984) focused on how class positions become "fractionated" between dominant and dominated groups, based upon the types and amounts of capital their members inherit or otherwise acquire, and the ways they are able to convert those types into resources supporting their aspirations. Members of cultural groups utilize these resources in their practices of everyday life, in order to gain strategic advantage, and to reconcile themselves to the pressing conditions of their existence. Crucially, Bourdieu argued that these processes manifest through our public performance of judgements of taste and preference. He argued that these judgments are not merely aesthetic: they are instead tied to social positions developed within fields, and their deployment constitutes an act of positioning - a bid for the attribution by others of status which distances us from undesirable socio-economic identities. 
Bourdieu (1990) subsequently emphasized how social actors constitute symbolic orders through their intuitive, unconscious embodiment of social structure (i.e., as an acquired 'disposition' for enacting particular forms of thought, feeling, belief, and action). He used the term habitus to designate related systems of embodied knowledge and cultural standards for assessing the competence of practices, arguing that such schemes of classification are inextricably tied to mechanisms which reproduce forms of inequality. One of those mechanisms involves our cultivation of symbolic capital (Bourdieu, 1979/1984) - the ability to naturalize other forms of capital and their effects as-if universal, legitimate and inevitable. The imposition of these modes of perception by elites on dominated groups, Bourdieu argued (1990), constitutes symbolic violence. Fields can only exist, he concluded, as long as social actors possess the dispositions that are necessary to constitute them as orderly sites of meaningful relations. As a result, no field is completely stable. Change may come about as its members recognize incongruent and underdetermined relations between their motives, their available resources, and the outcomes of their practices.

We are of course interested here in Bourdieu's (1988) application of this theory to critique the habitus of the higher-educational field. Specifically, Bourdieu was concerned with the role of academic institutions in maintaining social inequality, the exacerbation of that inequality by neo-liberal globalization, and the potential for social science to subvert its hegemony (Bourdieu \& Wacquant, 1999). Bourdieu questioned how the ruling and intellectual classes manage to preserve their social privilege across generations, despite increasing evidence contradicting their claim that higher-educational systems produce equal opportunity and socio-economic mobility. Instead, his studies revealed that, in performing routine processes like admitting students, conferring degrees, and hiring, promoting, and fêting faculty members, the members of higher-educational institutions typically normalize systems of classification and standards of evaluation that correspond with logics of the dominant order.

In this process, Bourdieu closely examined the structure and culture of higher-educational institutions. He viewed the academic field as a site of fierce, ongoing struggle (albeit sublimated through bureaucratic procedure and intellectual abstraction), conducted among the members of various disciplinary and professional groups. This struggle manifested as their members sought to alternately defend and transform existing systems for controlling their internal operations, and the ethical and political consequences of those operations for larger society. Bourdieu subsequently differentiated categories of academic players, based upon their types and degrees of available power. He noted, for example, that elite universities typically favored academic disciplines possessing high degrees of "temporal power," based upon their fulfillment of state requirements for the production of essential professionals (e.g., lawyers, doctors and priests). Disciplines possessing low degrees of that power enjoyed an upside, however - relative institutional freedom to pursue their distinctive intellectual passions. Additionally, Bourdieu distinguished between disciplines displaying "scientific" power (i.e., intellectual prestige achieved through traditional scholarly activities of teaching and research) and more instrumental forms of "academic" power associated with the localized reproduction of institutional structure (e.g., the over-representation of particular faculty groups on university committees that award competitive research funding). Other relevant factors here include how the members of academic-disciplines differ in their socio-economic backgrounds, personal incomes, predominant attitudes toward social and political issues, and the cultural preferences and practices they display in their private lives (Huber, 1990). 
Bourdieu's work thus guides researchers to investigate how the members of academic disciplines work to cultivate, translate, and promote their distinctive knowledge in order to secure their positions in local institutional hierarchies, and also to achieve external validation in the larger social order. Significantly, Bourdieu emphasized that this struggle is conducted over immediate and mundane issues (e.g., budgetary shortfalls, ethical lapses, etc.), but also more reflexively - as academic groups contest the logics (i.e., criteria) by which their relative forms of capital are alternately differentiated, evaluated, and stratified.

For our purposes, it is significant that Bourdieu viewed the social sciences as occupying a unique - if conflicted - position in academic fields: they simultaneously enjoy relative freedom to pursue their chosen lines of inquiry, while producing knowledge that critiques "the monopoly of legitimate thought and discourse" produced by higher-status disciplines such as law and business. Additionally, we note that Bourdieu recognized research methodology as a type of "scientific capital" within academic fields. He sarcastically condemned, for example, the fetishization of methodology displayed by some of his positivist colleagues in the international field of political sociology: "One realizes that these scholastic codifications of the rules of scientific practice are inseparable from the project of building a kind of intellectual papacy, replete with its international corps of vicars, regularly visited or gathered together in concilium and charged with the exercise of rigorous and constant control over common practice..." (Bourdieu, 1985/2007, p. 1252). As a result, the revision by a discipline of its existing methodology might be compared to innovation occurring in the cultural field of sports: "The appearance of a new sport or a new way of practicing an already established sport ... causes a restructuring of the space of sporting practices and a more or less complete redefinition of the meaning attached to the various practices" (Bourdieu, 1978/1993, p. 350). Finally, Bourdieu was a passionate critic of textual economies which supported the globalization of academic disciplines - particularly their ability to reinforce the power of Anglo-American professionals to 'consecrate' the value derived by international researchers from adopting related knowledge and practice (Bourdieu \& Wacquant, 1999, p. 46).

Applying Bourdieu's theory to our proposed project comes with some caveats. For example, Bourdieu's analysis has been critiqued for the limited generalizability of its findings concerning a specific (i.e., French) cultural setting - including its increasingly outdated depiction of intellectual groups enjoying relative insulation from economic colonization (Marginson, 2008). Additionally, Bourdieu's did not typically conceptualize single disciplines as "fields" - preferring instead to model a large complex of forces which challenge the presumed independence and stability of those contexts. Indeed, significant intellectual work is required to cultivate the implications of Bourdieu's arguments for reflexive critique by social scientists of the overarching contingency of their entire disciplines, and not merely of their specific practices for collecting, analyzing, or representing data (Robbins, 2007). Ideally, such projects would follow Bourdieu's claim that "only a genuine history of the genesis of ideas about the social world, combined with an analysis of the social mechanisms of the international circulation of those ideas, could lead intellectuals ... to a better mastery of those instruments with which they argue" (Bourdieu \& Wacquant, 1999, pp. 51-52). Fortunately for our purposes, Naidoo (2004) argues that this goal is best served by methodological strategies emphasizing the specific processes by which academic capital is reproduced within and between local institutions, and also "the [distinctive] content and internal structuring of knowledge" (p. 468) within academic fields.

As a result, we may derive the following research questions from this tradition: 
- How do the existing possession and use of capital among the members of an academic-disciplinary community shape their initial orientation to the potential value of qualitative research methods? How do specialists within that community utilize their capital to promote particular forms and practices of qualitative research methods?

- How is a uniquely cultural mode of demand for 'qualitative research methods' produced within academic disciplines? How do their members acquire a "taste" for its knowledge and practice? How are its perceived benefits articulated with existing schemes for classifying legitimately "academic" enterprise (Naidoo, 2004, p. 466)?

- How are particular academic fields transformed through the disciplinary development of qualitative research methods? How does this development create new forms of academic and scientific capital - "gains in distinction" (Bourdieu, 1978/1993, p. 346), which serve "position-taking" by academic groups in ongoing struggle conducted within and between disciplines? Put another way: How does the disciplinary adoption of qualitative methods achieve “distributional significance" among its constituents? (Bourdieu, 1978/1993, p. 352)?

\section{Conclusion}

This essay has explored changing contexts of professional-academic knowledge and practice in the contemporary era of neo-liberal globalization. It argues that, around the world, local communities of social scientists are currently engaged in negotiating the internationalization of both their disciplinary identities, and the potential resource of qualitative research methods. In this process, these communities operate with increased awareness of their unique, geopolitical situations as producers and consumers of methodological knowledge and practice. Our review has identified a current opportunity for empirical research of this phenomenon - one involving the reflexive use of qualitative research methods to study glocalized communities of qualitative researchers. The distinctive object of this nquiry involves the manifestation of those communities within overlapping contexts of national/regional culture, academic-disciplinary identity, and higher-educational institutionalization. The potential benefit of such inquiry includes enhanced knowledge of how local contingencies may influence the disciplinary appropriation of research methods to produce authentic communal artifacts.

To ensure its viability, this project requires diligent consideration of available theoretical resources. To that end, this essay has reviewed five available traditions, focusing on their key claims, their characteristic strengths and limitations, and the useful research questions they yield. While those traditions differ considerably, they also contribute to a composite picture of how such a project might work. Specifically, that agenda may be characterized by the following, distinctively qualitative commitments in gathering and interpreting evidence:

- Focus on specific communal meanings and practices - particularly those of symbolic expression and interpretation;

- Focus on the communal supervision of change - the concrete activities through which it is conceptualized and enacted by local-disciplinary members;

- Focus on the role of local, regional, national, and international textual economies in circulating both apparent exigencies, and resources for communal response;

- Focus on the role of existing communal norms, values, and beliefs in members' construction of qualitative research methods as a concern of local disciplinary identity; 
- Focus on the diversity and interdependency of social groups configured in local disciplinary appropriation of global qualitative methods. Focus on their negotiation of competing conceptions of those methods;

- Focus on the role of actors' motives and interests in engaging global qualitative methods as a strategic resource for their ongoing conduct of institutional competition and conflict;

- Focus on the related ethics and politics of that interaction - for example, the ways in which communal adoption of qualitative research methods alternately opens and forecloses potential paths of disciplinary development; and finally,

- Focus on actors' display of independent agency and creative participation in related processes, rather than assuming the inevitable determination of related outcomes by abstract, external forces.

Hopefully, these commitments will enable researchers to successfully cultivate the value of this line of inquiry. Regarding limitations, most obviously, this current proposal does not address methodological questions concerning the design and conduct of related data collection and analysis, or the representation of subsequent findings. Additionally, we should not presume that the theories discussed here exhaust relevant possibilities for this project, or that discussion here of any particular theory has completely resolved its utility. For now, however, we must leave these questions and gaps to be addressed in separate statements, in reports of concrete studies, and through communal assessment of evolving results. In this process, the global community of qualitative research may continue to fashion and circulate images of itself, for itself, striving to increase their accuracy, completeness, and value.

\section{References}

1. Adam, F., \& Podmenik, D. (2005, September). Qualitative research in a changing epistemic context. The case of a small social science community. In Forum Qualitative Sozialforschung/Forum: Qualitative Social Research (Vol. 6, No. 3). http://www.qualitative-research.net/index.php/fqs/article/viewArticle/14

2. Alasuutari, P. (2004). The globalization of qualitative research. In C. Seale, G. Gobo, J. Gubrium, \& D. Silverman (Eds.), Qualitative research practice (pp. 595-608). London: Sage.

3. Angermüller, J. (2005, September). "Qualitative" Methods of Social Research in France: Reconstructing the Actor, Deconstructing the Subject. In Forum Qualitative Sozialforschung/Forum: Qualitative Social Research (Vol. 6, No. 3). http://www.qualitative-research.net/index.php/fqs/article/viewArticle/8

4. Becher, T., \& Parry, S. (2005). The endurance of the disciplines. In I. Bliekle \& M. Henkel (Eds.), Governing knowledge (pp. 133-144). Netherlands: Springer.

5. Becher, T., \& Trowler, P. (2001). Academic tribes and territories: Intellectual enquiry and the culture of disciplines. McGraw-Hill Education (UK).

6. Borg, E. (2003). Discourse community. ELT Journal, 57 (4), 398-400.

7. Bourdieu, P. (1977). Outline of a Theory of Practice (Vol. 16). Cambridge University Press.

8. Bourdieu, P. (1978/1993). How can one be a sports fan? In S. During (Ed.), The cultural studies reader (427-440). London: Routledge.

9. Bourdieu, P. (1979/1984). Distinction: A social critique of the judgement of taste. Harvard University Press.

10. Bourdieu, P. (1985/2007). The market of symbolic goods. In D. H. Richter, The critical tradition: Classic texts and contemporary trends (pp. 1231-1253). Boston: Bedford/St. Martin's.

11. Bourdieu, P. (1988). Homo academicus. Stanford University Press.

12. Bourdieu, P. (1990). The logic of practice. Stanford University Press. 
13. Bourdieu, P., \& Wacquant, L. (1999). On the cunning of imperialist reason.Theory, Culture \& Society, 16(1), 41-58.

14. Charmaz, K. (2014). Grounded theory in global perspective: Reviews by international researchers. Qualitative Inquiry, 20(9), 1074-1084.

15. Churchman, D., \& Stehlik, T. (2007). Transforming academic work: Communities of practice in Australian universities. Journal of Organisational Transformation \& Social Change, 4(3), 263-278.

16. Dearing, J. W. (2006). Communication as diffusion. In G. Shepherd, J. St. John, \& T. Striphas (Eds.), Communication as ...: Perspectives on theory (174-179). Thousand Oaks, CA: Sage.

17. Duff, P. A. (2010). Language socialization into academic discourse communities. Annual Review of Applied Linguistics, 30, 169-192.

18. Eberle, T. S., \& Elliker, F. (2005, September). A cartography of qualitative research in Switzerland. In Forum Qualitative Sozialforschung/Forum: Qualitative Social Research (Vol. 6, No. 3). http://www.qualitative-research.net/index.php/fqs/article/viewArticle/13

19. Fish, S. E. (1980). Is there a text in this class?: The authority of interpretive communities. Harvard University Press.

20. Fiske, J. (1992). Cultural studies and the culture of everyday life. In L. Grossberg, C. Nelson, \& P Treichler (Eds.), Cultural Studies (pp. 154-173). New York: Routledge.

21. Flick, U. (2014). Challenges for qualitative inquiry as a global endeavor: Introduction to the special issue. Qualitative Inquiry, 20(9), 1059-1063.

22. Flick, U., \& Röhnsch, G. (2014). Migrating diseases, triangulating approaches: Applying qualitative inquiry as a global endeavor. Qualitative Inquiry, 20(9), 1096-1109.

23. Flick, U. (2015). Qualitative Inquiry - 2.0 at 20? Developments, trends, and challenges for the politics of research. Qualitative Inquiry, 21 (7): 599-608.

24. Goodall, H. L. (1999). Casing the academy for community. Communication Theory, 9(4), 465-494.

25. Henwood, K., \& Lang, I. (2005, September). Qualitative Social Science in the UK: A Reflexive Commentary on the" State of the Art". In Forum Qualitative Sozialforschung/Forum: Qualitative Social Research (Vol. 6, No. 3). http://www.qualitative-research.net/index.php/fqs/article/view/16/35

26. Hsiung, P. C. (2012). The globalization of qualitative research: Challenging Anglo-American domination and local hegemonic discourse. Forum Qualitative Sozialforschung / Forum: Qualitative Social Research, 13 (1), Art. 21, http://nbn-resolving.de/urn:nbn:de:0114-fqs1201216.

27. Huber, L. (1990). Disciplinary cultures and social reproduction. European Journal of Education, 25, 241-261.

28. Hymes, D. (1972). On communicative competence. Sociolinguistics, 3, 269-293.

29. Jawitz, J. (2007). New academics negotiating communities of practice: Learning to swim with the big fish. Teaching in Higher Education, 12(2), 185-197.

30. Klein, H. K., \& Hirschheim, R. (2008). The structure of the IS discipline reconsidered: Implications and reflections from a community of practice perspective. Information and Organization, 18(4), 280-302.

31. Kleypas, K. L., \& McDougall, J. I. (Eds.). (2011). The American-style university at large: Transplants, outposts, and the globalization of higher education. Lexington Books.

32. Knoblauch, H., Flick, U., \& Maeder, C. (2005, October). The state of the art of qualitative research in Europe. In Forum Qualitative Sozialforschung/Forum: Qualitative Social Research (Vol. 6, No. 3). www.qualitative-research.net/index.php/fqs/article/download/3/8

33. Konecki, K. T., Kacperczyk, A. M., \& Marciniak, L. T. (2005, September). Polish Qualitative Sociology. The General Features and Development. InForum Qualitative Sozialforschung/Forum: Qualitative Social Research (Vol. 6, No. 3). http://www.qualitative-research.net/index.php/fqs/article/view/12/25

34. Lamont, M., \& Molnár, V. (2002). The study of boundaries in the social sciences. Annual review of sociology, 28, 167-195.

35. Lindlof, T. R. (forthcoming). From interpretive community to produser community: A media audience paradigm shift. In R. A. Lind (Ed.), Produsing Theory in a Digital World: The Intersection of Audiences and Production in Contemporary Theory, Vol. 2. New York: Peter Lang. 
36. Mannheim, K. (1952/2009). The sociological problem of generations. Available from http://1989after1989.exeter.ac.uk/wp-content/uploads/2014/03/01_The_Sociological_Problem.pdf.

37. Marginson, S. (2008). Global field and global imagining: Bourdieu and worldwide higher education. British Journal of Sociology of Education, 29(3), 303-315.

38. Marshall, H., \& Robinson, P. (2014). Generational differences in the early careers of teaching sociologists. Journal of Sociology, 1440783313514642.

39. McDonald, J., \& Star, C. (2008). The challenges of building an academic community of practice: An Australian case study. In Proceedings of the 31st HERDSA Annual Conference: Engaging Communities. Higher Education Research and Development Society of Australasia.

40. Naidoo, R. (2004). Fields and institutional strategy: Bourdieu on the relationship between higher education, inequality and society. British Journal of Sociology of Education, 25(4), 457-471.

41. Olsen, L. (1993). Research on discourse communities: An overview. In R. Spilka (Ed.), Writing in the workplace: New research perspectives, 181-195. Carbondale: Southern Illinois University Press.

42. Otten, M., Allwood, J., Aneas, M. A., Busch, D., Hoffman, D., \& Schweisfurth, M. (2009). Qualitative research on intercultural communication. In Forum Qualitative Sozialforschung/Forum: Qualitative Social Research (Vol. 10, No. 1). http://www.qualitative-research.net/index.php/fqs/article/view/1248

43. Pilcher, J. (1994). Mannheim's sociology of generations: an undervalued legacy. British Journal of Sociology, 45 (3): 481-495.

44. Puebla, C., Figaredo, D., Faux, R., Kölbl, C., \& Packer, M. (2006). Editorial: About qualitative research epistemologies and peripheries. Forum Qualitative Sozialforschung / Forum: Qualitative Social Research, 7(4), Art. 4, http://nbn-resolving.de/urn:nbn:de:0114-fqs060444

45. Robbins, D. (2007). Sociology as Reflexive Science: On Bourdieu's Project.Theory, Culture \& Society, 24(5), 77-98.

46. Rogers, E. M. 2003. Diffusion of innovations (5th Ed.). New York: Free Press.

47. Schubotz, D. (2005, September). Beyond the Orange and the Green. The diversification of the qualitative social research landscape in Northern Ireland. In Forum Qualitative Sozialforschung/Forum: Qualitative Social Research (Vol. 6, No. 3). http://www.qualitative-research.net/index.php/fqs/article/viewA rticle/11.

48. Somekh, B., Burman, E., Delamont, S., Meyer, J., Payne, M., \& Thorpe, R. (2005). Research communities in the social sciences. In B. Somkekh \& C. Lewin, Research methods in the social sciences, (1-13). Thousand Oaks, CA: Sage.

49. Taylor, B., \& Lindlof, T. (2013). Travelling methods: Tracing the globalization of qualitative communication research. Romanian Journal of Communication and Public Relations, 15(3), 11-30.

50. Torrance, H. (2014). Qualitative research in the United Kingdom: Short-term problems, long-term issues. Qualitative Inquiry, 20(9), 1110-1118.

51. Umpleby, S. A., Mekhonoshin, K., \& Vladimirov, Z. (2009). A global university for a global village. Cultural Studies- Critical Methodologies, 9(3), 446-461.

52. Valles, M. S., \& Baer, A. (2005, September). Qualitative social research in Spain: Past, present, and future. A portrait. In Forum Qualitative Sozialforschung/Forum: Qualitative Social Research (Vol. 6, No. 3). http://www.qualitative-research.net/index.php/fqs/article/viewArticle/15.

53. Wagner, C., Garner, M., \& Kawulich, B. (2011). The state of the art of teaching research methods in the social sciences: Towards a pedagogical culture. Studies in Higher Education, 36(1), 75-88.

54. Weil, S. (2005, September). Qualitative methods in Israel. In Forum Qualitative Sozialforschung/Forum: Qualitative Social Research (Vol. 6, No. 3). http://www.qualitative-research.net/index.php/fqs/article/viewArticle/9.

55. Wenger, E. (no date). Communities of Practice: A Brief Introduction. Available at: http://wenger-trayn er.com/introduction-to-communities-of-practice/. 